\title{
Urinary Exosomes and Their Cargo: Potential Biomarkers for Mineralocorticoid Arterial Hypertension?
}

\author{
Eric R. Barros and Cristian A. Carvajal* \\ Center of Translational Endocrinology (CETREN), Faculty of Medicine, Endocrinology Department, Pontificia Universidad \\ Católica de Chile, Santiago, Chile
}

OPEN ACCESS

Edited by:

Carlos Salomon,

The University of

Queensland, Australia

Reviewed by:

Michelle L. Gumz,

University of Florida,

United States

Manuel D. Gahete,

Instituto Maimónides

de Investigación Biomédica de

Córdoba, Spain

*Correspondence:

Cristian A. Carvajal

ccarvaja@med.puc.cl

Specialty section:

This article was submitted to Systems and Translational

Endocrinology,

a section of the journal

Frontiers in Endocrinology

Received: 01 May 2017

Accepted: 23 August 2017

Published: 08 September 2017

Citation:

Barros ER and Carvajal CA (2017) Urinary Exosomes and Their Cargo:

Potential Biomarkers for Mineralocorticoid

Arterial Hypertension?

Front. Endocrinol. 8:230.

doi: 10.3389/fendo.2017.00230
Arterial hypertension (AHT) currently affects approximately $40 \%$ of adults worldwide, and its pathological mechanisms are mainly related to renal, vascular, and endocrine systems. Steroid hormones as aldosterone and cortisol are highly relevant to human endocrine physiology, and also to endocrine hypertension. Pathophysiological conditions, such as primary aldosteronism, affect approximately $10 \%$ of patients diagnosed with $\mathrm{AHT}$ and are secondary to a high production of aldosterone, increasing the risk also for cardiovascular damage and heart diseases. Excess of aldosterone or cortisol increases the activity of the mineralocorticoid receptor (MR) in epithelial and nonepithelial cells. Current research in this field highlights the potential regulatory mechanisms of the MR pathway, including pre-receptor regulation of the MR (action of 11BHSD2), MR activating proteins, and the downstream genes/proteins sensitive to MR (e.g., epithelial sodium channel, NCC, NKCC2). Mineralocorticoid AHT is present in $15-20 \%$ of hypertensive subjects, but the mechanisms associated to this condition have been poorly described, due mainly to the absence of reliable biomarkers. In this way, steroids, peptides, and lately urinary exosomes are thought to be potential reporters of biological processes. This review highlight exosomes and their cargo as potential biomarkers of metabolic changes associated to mineralocorticoid AHT. Recent reports have shown the presence of RNA, microRNAs, and proteins in urinary exosomes, which could be used as biomarkers in physiological and pathophysiological conditions. However, more studies are needed in order to benefit from exosomes and the exosomal cargo as a diagnostic tool in mineralocorticoid AHT.

Keywords: arterial hypertension, exosomes, biomarker, water-electrolyte balance, microRNA, urine, sodium channels

\section{ARTERIAL HYPERTENSION (AHT)}

Arterial hypertension is a multifactorial disease with a complex pathogenesis involving several systems. Different etiologies of AHT are known to occur from the interplay between genetic and environmental factors that lead to changes in biological pathways and eventually trigger this complex disorder that primarily involves the cardiovascular system (1-3). AHT is a major risk factor for stroke, myocardial infarction, heart failure, and end-stage renal disease. Worldwide, approximately $40 \%$ of adults over 25 years old are affected by AHT, contributing to $45-50 \%$ of deaths due to heart disease and stroke $(4,5)$, making AHT a major concern for public health, particularly 
in western countries (6-11). The pathogenesis of AHT involves the renal, vascular, and endocrine systems (12-15), affecting mainly sodium-water reabsorption and arterial vasoconstriction. Pathological conditions, such as primary aldosteronism (PA), are responsible for up to $5-10 \%$ of patients diagnosed with AHT, and involve an increased production of aldosterone that leads to AHT, cardiovascular damage, heart diseases (16-18), and renal and immune alterations (19-23). Aldosterone is a mineralocorticoid hormone with non-genomic and genomic actions; the latter through the mineralocorticoid receptors (MR) can alter sodium transport in renal collecting ducts, increase water uptake, blood volume, and eventually raise blood pressure. Along with effects of aldosterone in AHT, different studies in cells, animal models, and human trials through the analysis of serum and urinary markers have confirmed the pathogenic role of aldosterone on inflammation, endothelial dysfunction, oxidative stress, and fibrosis $(20,24,25)$. Other factors, as novel proteins associated to aldosterone have also been reported to independent activate or enhance the MR action, such as a small GTP-ase $\operatorname{Rac1}(26,27), \operatorname{GPER}(28)$, and the co-activator RACK1 (29). However, only Racl has been described as component of exosomes (http://exocarta.org/download). GPER (previously known as GPR30) is a recently recognized G protein-coupled receptor implicated in mediating some of the rapid effects of steroid hormones, especially aldosterone. GPER protein is activated by aldosterone, but its relation with exosomes and mineralocorticoid AHT has not been studied to date.

Most studies about primary AHT have being focused in genetic alterations associated with the onset and progression of AHT affecting cardiac, endocrine, and renal systems (1, 2, 30-32). Gene-specific (31, 33, 34), genome-wide association (35-39), and epigenetic studies $(40,41)$ support the knowledge about the genetic components related to AHT. Several phenomena that regulate gene expression through genetics and epigenetics are emerging to understanding of AHT development $(40,42,43)$. Most of the studies addressing the role of epigenetics in human AHT $(44,45)$ have focused their interest on DNA methylation $(46,47)$ and non-coding RNAs such as microRNAs (miRNAs) (41).

Gene expression is a coordinated system regulating specific synthesis and interaction of RNA, miRNAs, and proteins. All of them can be also carried and potentially transferred to other cells (recipient cells) through nanovesicles called exosomes, where they regulate further cellular and metabolic processes (48). Identification of cell-specific RNA and proteins contained in exosomes isolated from different biofluids, may be a promising biological tool to identify early signs of AHT (49-51). This review highlight exosomes and their cargo as potential biomarkers or biological reporters of metabolic changes associated to mineralocorticoid AHT.

\section{EXOSOMES ARE CARRIERS OF BIOLOGICAL INFORMATION}

Exosomes and microvesicles are involved in several metabolic processes (52) initially proposed in the 1980s (53), described in tissues (54), body fluids (55) and considered to be vehicles for eradicating cell waste products (56). They are currently defined as extracellular vesicles of endosomal origin, with a spherical shape and a phospholipid bilayered structure of 30-150 nm diameter, carrying exosomal markers (e.g., CD63, HSP70) and a buoyant density of 1.23-1.16 g/L (57-59). Exosomes have important functions in immunology, cancer, coagulation, and many others aspects of human physiology, as carriers of information including, proteins (60), lipids (61), mRNA, miRNA (48), and DNA (62).

Exosomes act through receptor-ligand interactions, by attaching/fusing with the target-cell membrane or by being internalized by the recipient cells (63) performing cell-to-cell communication and the intercellular exchange of proteins and nucleic acids, with relative stability against proteinases and RNAses (48). mRNAs horizontally transferred from exosomes to neighboring cells can be translated into proteins, and miRNAs can regulate acceptor mRNA expression (64). Exosomes contain a specific subset of cellular proteins, some of which depend on the cell type of origin, and others that are only found in exosomes regardless of the cell type of origin (57).

\section{EXOSOMES AND EXOSOMAL CARGO ARE POTENTIAL NOVEL BIOMARKERS FOR ARTERIAL HYPERTENSION}

Arterial hypertension is mainly associated with alterations in the cardiovascular and renal systems, in which there is great interest for discovering new biomarkers, highlighting the potential role of exosomes. Human blood, saliva, and urine are biofluids that constitute a source of non-invasive, convenient and easy to access biomarkers that can be collected many times over long periods of time. Spot urine and 24-h urine is the focus for the identification of novel peptide, steroidal, or exosomal biomarkers with a potential role in diagnosis and classification of diseases related to renal system $(65,66)$.

Recent urinary proteomic studies have identified potential protein biomarkers of renal disease (67) such as nephrin (68) or podocin (69), but none of them have been translated into regular clinical practice. This is probably because free urinary proteins are often scarce, and frequently reabsorbed in the tubular renal systems or subjected to proteolytic digestion (70), similar to urinary RNA, which is degraded by RNAses in renal tissues (71); therefore, exosomes and their cargo, which are protected by a plasmatic membrane that is resistant to these influences, seem to be a suitable source of urinary biomarkers (72).

\section{URINARY EXOSOMES, RENIN- ANGIOTENSIN-ALDOSTERONE SYSTEM (RAAS) AND MINERALOCORTICOID AHT}

Urinary exosomes originate from cells lining the nephron lumen and the urinary tract (70). Plasmatic exosomes cannot cross the glomerular filtration apparatus; therefore, urinary exosomes originate exclusively from luminal epithelial renal cells (73). Proteins detected in urinary exosomes are a reflection of the proteins in renal tissues $(74,75)$ and from acute injured sites 
distant from the urinary tract (e.g., liver injury). The former increase their protein abundance upon stimulation of the reninangiotensin-aldosterone system (RAAS), which is an important blood pressure regulator (65). Exosomal RNAs, miRNAs, and proteins can mirror gene expression changes in kidney diseases $(70,76)$ promising to be effective and non-invasive biomarkers for renal disease and may be used as surrogate markers of RAAS activation, affecting expression of the epithelial sodium channel (ENaC) (OMIM: 600228), the thiazide-sensitive sodiumchloride-cotransporter (NCC) (OMIM: 600968) $(77,78)$ among others. The complexity of the urinary proteome hinders the detection of low-abundance proteins that may have pathophysiological relevance; therefore, the evaluation of urine exosomal proteins, which represent approximately $3 \%$ of the whole urine proteome, reduces the complexity of studying the whole urine proteome (79). These urinary proteins may originate from renal physiological processes that occur within the kidneys and/ from exosome secretion (72). Comprehensive studies have been conducted on the proteome of urinary exosomes, revealing that they contain a variety of cell-specific proteins/transporters from the kidney and from the urogenital tract $(80,81)$, that could be useful in the diagnosis of mineralocorticoid AHT.

\section{WATER-ELECTROLYTIC BALANCE: TAKING ADVANTAGE OF EXOSOMES}

\section{Sodium Transporters}

There is considerably more research on the use of urinary exosomes than circulating exosomes for the diagnosis of hypertension, probably because most sodium transporter are present on the apical plasma membrane of the kidney epithelium and urinary exosomes are released to the lumen of the nephron under hormonal regulation. Sodium channels and specific miRNAs expression in exosomes are susceptible to the action of aldosterone alone and the RAAS $(49,65,82)$. The RAAS and the kidneys play a pivotal role in blood pressure regulation (83) with sodium channels acting as crucial elements in the regulation of the electrolyte balance and blood pressure $(84,85)$. Some of the main players in sodium/water balance are the NHE3 (SLC9A3, sodium-hydrogen exchanger 3) (86) present in the renal proximal tubule, the $\mathrm{Na}-\mathrm{K}-\mathrm{Cl}$ cotransporter NKCC2 (SLC12A1) in the thick ascending loop of Henle (LoH) $(84,87,88)$ and the NCC (SLC12A3) along with the ENaC (SCNN1) on the distal nephron (distal convoluted tubules and collecting duct). Altered function of these leads to hypertensive syndromes, such as Liddle (increased ENaC activity) (89) and Gordon (WNK4-NCC) (90, 91), or hypotensive syndromes, such as Gitelman (NCC) (92) and Bartter (NKCC2) (30) (see Figure 1).

Patients diagnosed with Gordon syndrome had a fourfold increase in the abundance of NCC in urinary exosomes when compared to controls (90); a recent publication in patients under exogenous mineralocorticoid (fludrocortisone) administration showed a reduction of $48 \%$ in the phosphorylated NCC (pNCC)/ NCC ratio along with a rapid increase in the abundance of NCC and pNCC in urinary exosomes, possibly through the WNK pathway (77). Interestingly, Castagna et al. in 2015 showed that exosomal and urinary NCC is under circadian regulation (93). Urinary exosomes from patients diagnosed with the Gitelman and Bartter type- 1 syndromes, showed almost undetectable levels of NCC and NKCC2 proteins, making feasible to discriminate between the syndromes and their severity through the exosomal protein content (94).

Urinary exosomes from mildly hypertensive patients on a low-sodium diet (activated RAAS) showed that a $11.4 \%$ of their total protein content changes ( 316 out of 2,775 proteins), with $4.1 \%$ of the proteins increasing and $7.3 \%$ decreasing the expression level. Here, the abundance of NCC, and the $\alpha, \beta$, and $\gamma$ subunits of $\mathrm{ENaC}$ increased under low-sodium diet or aldosterone infusion correlating with plasma aldosterone and urinary $\mathrm{Na} / \mathrm{K}$ ratio (65). This communication also highlights the presence of the $\gamma \mathrm{ENaC}_{[112-122]}$ peptide that increases nearly 20 -folds by both challenges (LS diet or under aldosterone infusion) and correlates with plasma aldosterone and urinary $\mathrm{Na} / \mathrm{K}$ ratio, while $\alpha \mathrm{ENaC}$ and NCC from urinary exosomes did not change under the same stimuli (65). Further evidence linking ENaC, exosomes, and AHT comes from Nielsen et al. (95) who studied pregnant women in normal and preeclamptic conditions (95) and from Olivieri et al. (96) who measured urinary exosomal prostasin from healthy subjects and found a correlation with aldosterone to renin ratio and urinary sodium (96).

Rat models of sodium imbalance show a correlation between the renal-tissue expression of NCC and NKCC2, and the expression of the same proteins on urinary exosomes (75). Urinary exosomes from rats under aldosterone infusion or low-sodium diet increased the levels of pNCC (97), similar to urinary exosomes from patients with PA, who had more pNCC than hypertensive patients, suggesting a possible role for exosomes as a PA biomarker (93). Similarly, an animal model of SpragueDawley rats under sodium restriction showed increased expression of fully processed $\mathrm{ENaC}$, with the $\alpha$ and $\gamma$ subunits in fully cleaved states, and the $\beta$-ENaC fully glycosylated in urinary exosomes (98).

\section{Aquaporins}

Aquaporins (AQPs) are renal membrane proteins involved in the transfer of water and solutes across cell membranes, influencing urine formation and water handling. At least eight isoforms are reported in renal tissues (AQP 1-4, 6-8, 11) (99). AQP1 is expressed in the kidney's proximal tubule cells, the thin descending LoH and the descending vasa recta, while AQP2 (anti-diuretic hormone-regulated water channel) is expressed in the principal cells of connecting tubules and collecting ducts (100-102).

Urinary exosomes have been observed carrying AQP1 and AQP2 $(80,103)$. AQP2 is under circadian regulation decreasing in the morning and increasing in the afternoon/evening (93). The exosomal protein levels of AQP1-2 correlate with the renal expression and reflect their action on renal cells (104). The other AQPs have not been found in urinary extracellular vesicles (99). Decreased levels of AQP1 have been observed in urinary exosomes from a renal rat ischemia reperfusion injury model, from the urine of human patients after renal transplantation (105) and in cultured cells after exposure to acetazolamide (diuretic acting on the nephron's proximal tubules) (106). 
In contrast, acetazolamide increases AQP1 in rat urinary exosomes without a decrease in the renal expression (107). Long-term effect of vasopressin or vasopressin analogs promotes extracellular vesicle uptake in renal epithelial cells (108), extracellular vesicle release in collecting duct cells, and enhance urinary excretion of exosomal AQP2 $(109,110)$ in murine kidney collecting duct cells (mCCDC11), rodents, and patients with central diabetes insipidus (111). The short-term effects of these hormones increase the abundance of urinary exosomal AQP2 protein (101) but reduces it under hypervolemic states (112). Regarding the mineralocorticoid pathway, there is a controversial relation between $\mathrm{AQP} 2$ expression, aldosterone and the MR activation (113).

\section{Renin-Angiotensin-Aldosterone System}

As stated previously, the RAAS is a major regulator of blood pressure acting over the renal, vascular, cardiac, and adrenal systems. Angiotensin II (Ang II) and the Ang II type I receptor (AT1R) play key roles that could be being driven by exosomes. In 2015, Pironti et al. showed that either cardiac overload or Ang-II stimulation, induced the release of exosomes to the circulation (mainly from cardiomiocytes) carrying functional $\mathrm{AT} 1 \mathrm{R}$, that move to cardiac/skeletal myocytes and resistance vessels, further regulating blood pressure (114), and probably improving their sensitivity to RAAS (82).

Angiotensin II besides elevating blood pressure, is also associated with inflammation mediated end-organ damage and fibrosis in AHT; hypertensive rat models (Ang II or L-NAME infused) release serum exosomes with decreased levels of miRNA-17 (ICAM-1 negative regulator) that when cultured with human coronary artery endothelial cells increase the protein expression of ICAM-1 and PAI-1, which are essential pro-inflammatory factors in vascular inflammation (115) providing evidence that hypertensive-related endothelial damage may be due to exosomes and their cargo. The association between urinary exosomes and renal RAAS has been poorly studied and only indirect evidence has been reported in the literature $(65,80,97)$.

\section{URINARY EXOSOMES AS CARRIERS OF miRNAs}

MicroRNAs are endogenous small RNA molecules of approximately 22 nucleotides that can control a target gene transcriptionally and posttranscriptionally (116) by complementarily binding the $3^{\prime}$ UTR of target mRNA $(117,118)$. miRNAs are involved in cellular processes including proliferation, development, metabolism, differentiation, and apoptosis. Individual miRNAs may regulate hundreds of genes, collectively $50-60 \%$ of the total transcriptome (119), suggesting that miRNAs can have pleiotropic biological effects. Deregulation of miRNA expression is linked to many human pathological conditions; however, few studies have evaluated the relationship between miRNA expression and regulation of the MR pathway, which has been associated mainly to gene expression downregulation at pre-receptor level, as occurs with 11BHSD2 $(120,121)$.
Different studies relate renal expression of miRNAs and AHT (122). In 2013, Gildea et al. studied the miRNAome of urinary exosomes (49) and found 45 miRNAs likely to be potential biomarkers that correlated with salt sensitivity or inverse salt sensitivity of blood pressure. Some of these miRNAs regulate signaling pathways associated to AHT, reflecting the metabolic activity of the kidney and particularly sodium handling (see Table 1).

\section{INTRARENAL COMMUNICATION MEDIATED BY EXOSOMES}

Exosomes are proposed to play a key role in the inter- and intra-cellular communication of renal epithelial tissues among the different nephron segments. The available literature shows scarce and indirect evidence of MR activity associated to intrarenal communication mediated by exosomes. However, a study by Jella et al. (50) showed that apical and basolateral exosomes secreted from a proximal tubule cell line (LLC-PK1) carrying active GAPDH that was taken up by cortical collecting duct cells (mpkCCD), which decreased its ENaC activity. This effect was mimicked in Xenopus 2F3 (distal tubule cells) and cortical collecting duct cells from SV129 wild-type mice in a GAPDH-dependent manner (50), providing information on how exosomes released on the proximal portion of the nephron can influence the activity of sodium channels in distal portions of the nephron (see Figure 1).

Another example of exosomal transferring, come from mCCDC11 cells (from cortical collecting duct epithelia) stimulated with synthetic vasopressin analogs, which release exosomes loaded with AQP2 at levels that correlate with the AQP2 expression of the cell of origin. These exosomes are capable of transferring functional amounts of AQP2 to cells that do not express it, inducing an increase in cellular water flow (110). This suggests that exosomal content is physiologically regulated by vasopressin and other hormones, through the loading of exosomes with functional proteins capable of regulating water homeostasis. On the other hand, fenoldopam and Ang II stimulate exosome release from human renal proximal tubule cells, which can then be taken up by human distal and collecting tubule cells, where the exosomes accumulate into multivesicular bodies and modulate the activity of reactive oxygen species downstream (73).

Finally, normal human urinary exosomes isolated and sequenced by RNA sequencing revealed that miR-10b-5p, miR10a-5p, miR30a-5p, miR26a-5p, and miR-30d-5p were the most abundant urinary miRNAs (51), confirming some miRNAs previously reported by Cheng et al. (71). Afterwards, human collecting duct cells and proximal tubular cells (HKC-8) were exposed to these isolated urinary exosomes. They were internalized and reduced the protein levels of ROMK, SGK1 and WNK1 in human collecting duct cells, and decreased the mRNA levels of the coupled neutral amino acid transporter 2 (SLC38A2) and its encoded protein SNAT2 in HKC-8 cells (51). These studies showed a potential functionality of urinary exosomes through miRNAs, suggesting that they carry specific miRNA families that target specific renal functions. 
TABLE 1 | Studies reporting miRNAs associated to genes or signaling pathways related to AHT.

\begin{tabular}{|c|c|c|c|c|c|c|c|}
\hline $\begin{array}{l}\text { Cell type } \\
\text { or zone }\end{array}$ & Gene & NCBI ID & OMIM & MicroRNA (miRNA) affecting gene & Sample source & Function related to AHT & Reference \\
\hline \multirow{4}{*}{$\begin{array}{l}\text { Collecting } \\
\text { duct tubule } \\
\text { (CDT) cells }\end{array}$} & NEDD4L & NG_029954.1 & 606384 & miRNA-30a-5p & Urine from healthy volunteers & $\begin{array}{l}\text { Aldosterone regulated sodium } \\
\text { reabsorption }\end{array}$ & (51) \\
\hline & HSD11B2 & NG_016549.1 & 218030 & miRNA-4474-3p & Urine from healthy volunteers & $\begin{array}{l}\text { Mineralocorticoid receptor (MR) } \\
\text { activation }\end{array}$ & (51) \\
\hline & SCNN1A & NG_011945.1 & 600228 & miRNA-4747-5p & Urine from healthy volunteers & $\begin{array}{l}\alpha E \mathrm{ENaC} \text {-mediated sodium } \\
\text { transport }\end{array}$ & (51) \\
\hline & SCNN1B & NG_011908.1 & 600760 & miRNA-138-1-3p & Urine from healthy volunteers & 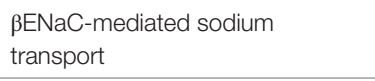 & (51) \\
\hline $\begin{array}{l}\text { Colon, } \\
\text { smooth } \\
\text { muscle cell, } \\
\text { and Henle's } \\
\text { loop }\end{array}$ & $\begin{array}{l}\text { SLC12A2 } \\
\text { (NKCC1) }\end{array}$ & NG_042286.1 & 600840 & $\begin{array}{l}\text { miRNA-26a-5p; miRNA16-5p; miRNA-181a-2-3p, } \\
\text { miRNA-101-3p; miRNA-203a; miRNA-561-3p; } \\
\text { miRNA-26b-5p; miRNA-15b-5p } \\
\text { miRNA-15a-5p; miRNA-424-5p } \\
\text { miRNA-4524b-5p; miRNA-195-5p } \\
\text { miRNA-218-5p; miRNA-374b-3p }\end{array}$ & Urine from healthy volunteers & $\begin{array}{l}\text { NKCC1-mediated sodium, } \\
\text { potassium, and chloride transport }\end{array}$ & (51) \\
\hline Henle's loop & $\begin{array}{l}\text { SLC12A1 } \\
\text { (NKCC2) }\end{array}$ & NG_021301.1 & 600839 & $\begin{array}{l}\text { miRNA-16-5p; miRNA-561-3p; miRNA-3662; } \\
\text { miRNA-335-3p; miRNA-15b-5p; miRNA-15a-5p; } \\
\text { miRNA-424-5p; miRNA-195-5p; miRNA-548k }\end{array}$ & Urine from healthy volunteers & $\begin{array}{l}\text { NKCC2-mediated sodium, } \\
\text { potassium, and chloride transport }\end{array}$ & (51) \\
\hline $\begin{array}{l}\text { Proximal } \\
\text { tubule cells }\end{array}$ & $A Q P 1$ & NG_007475.2 & 107776 & miRNA-128 & Urine from healthy volunteers & Water balance & (51) \\
\hline CDT cells & $A Q P 2$ & NG_008913.1 & 107777 & miRNA-4747-5p & Urine from healthy volunteers & Water balance & (51) \\
\hline CDT cells & NR3C2 & NG_013350.1 & 600983 & $\begin{array}{l}\text { miRNA-28-3p; miRNA-320-a; miRNA-205-5p; } \\
\text { miRNA-431-5p; miRNA-421; miRNA-135a-5p; } \\
\text { miRNA-409-3p; miRNA-186-5p; miRNA-211-5p; } \\
\text { miRNA-129-5p; miRNA-873-3p; miRNA-204-5p }\end{array}$ & Urine from healthy volunteers & MR activation & (51) \\
\hline \multirow[t]{5}{*}{ Ubiquitous } & ICAM1 & & & miRNA-17 & Rat urine from hypertension models (Ang II and L-NAME) & Vascular inflammation & (115) \\
\hline & $L C O R$ & & & miRNA-615-5p & $\begin{array}{l}\text { Human urinary exosomes from salt-sensitive or inverse salt } \\
\text { sensitivity patients }\end{array}$ & Upregulation of PPAR $\gamma$ & (49) \\
\hline & EGFR & & & miRNA-221, miRNA-222 & $\begin{array}{l}\text { Human urinary exosomes from salt-sensitive or inverse salt } \\
\text { sensitivity patients }\end{array}$ & EGFR pathway & (49) \\
\hline & $\begin{array}{l}\text { PIK3R1, } \\
\text { PTEN }\end{array}$ & & & miRNA-29a-3p & $\begin{array}{l}\text { Human urinary exosomes from salt-sensitive or inverse salt } \\
\text { sensitivity patients }\end{array}$ & $\begin{array}{l}\text { Blockade of the TGF- } \beta \text { PI3k-Akt } \\
\text { pathway }\end{array}$ & (49) \\
\hline & AML1/ETO & & & miRNA-193a-5p & $\begin{array}{l}\text { Human urinary exosomes from salt-sensitive or inverse salt } \\
\text { sensitivity patients }\end{array}$ & PTEN/PI3K signaling pathway & (49) \\
\hline
\end{tabular}




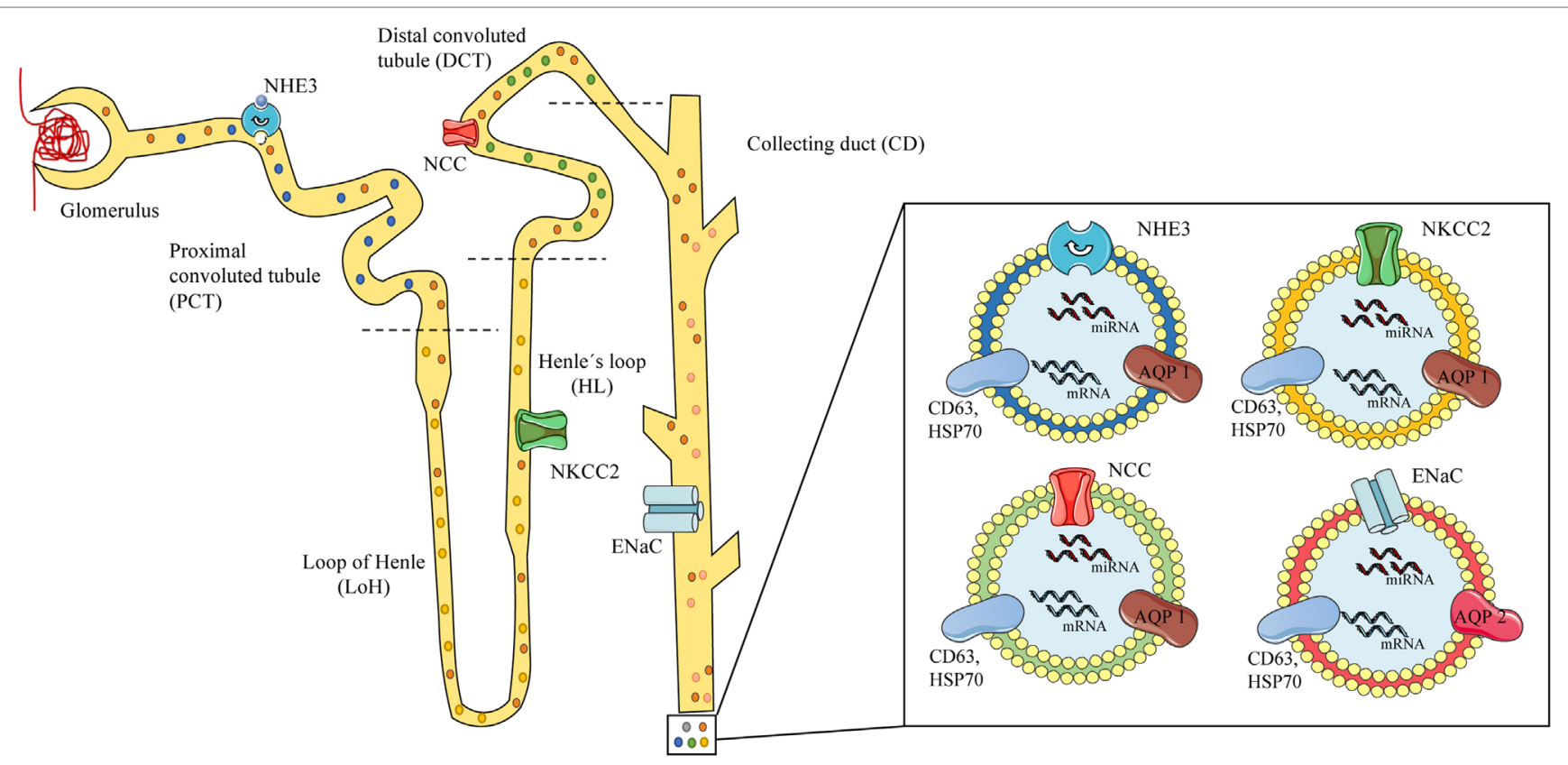

FIGURE 1 | Scheme of urinary exosomes released from different nephron segments. On the left, a scheme of the glomerulus and nephron showing exosomes released and traveling through the tubules carrying proteins or RNAs from the different segments of the nephron, containing specific channels associated to mineralocorticoid arterial hypertension. Specific local expression of sodium channels may be associated to the exosomal cargo: NHE3 from the proximal convoluted tubule (PCT) (blue exosome), NKCC2 from the loop of Henle (LoH) (yellow exosome), NCC from the distal convoluted tubule (green exosome), and epithelial sodium channel from the collecting duct (red exosomes). On the right, urinary exosomes (bilayered nanovesicles of 30-120 nm diameter) contain specific proteins (e.g., sodium channels), mRNA, and microRNA (miRNA), and show typical markers (CD63, HSP70) along with renal proteins (AQP1-2). Model based on references $(49-51,73,80)$.

\section{CONCLUSION}

There is a growing evidence indicating that exosomes play a role in cardiovascular and renal physiology, where mineralocorticoid AHT could benefit from the discovery of effective biomarkers. Exosomes possess a variety of biological information, and urinary exosomes mainly carry RNA and proteins could mirror biological events in the kidneys, which can be a useful a tool for identifying and studying metabolic changes in renal physiological and pathophysiological conditions. This review shows current evidence about urinary exosomes carrying mRNA, miRNAs, and specific sodium channels (ENaC, NCC, NKCC2), which could reflect their abundance in renal tissue and be related to metabolic pathways associated with mineralocorticoid AHT. Therefore, the information carried by exosomes could be beneficial for diagnosing different subtypes of AHT and enabling more appropriate treatment and further improving the quality of life for patients. Although progress in recent years has been made to elucidate the role of exosomes, many questions regarding their specific functions of urinary

\section{REFERENCES}

1. Padmanabhan S, Caulfield M, Dominiczak AF. Genetic and molecular aspects of hypertension. Circ Res (2015) 116:937-59. doi:10.1161/ CIRCRESAHA.116.303647 exosomes along the nephron and their response to different stimulus and pathological conditions still need more comprehensive answers. Further studies are needed to determinate the potential benefits of exosomes in mineralocorticoid AHT.

\section{AUTHOR CONTRIBUTIONS}

EB and CC drafted the manuscript and prepared figures and tables, helped with writing the manuscript and designing the figure and table, critically reviewed and revised the manuscript, and read and approved the final version of the manuscript.

\section{FUNDING}

This work was supported by grants CONICYT-FONDECYT 1150437, 1160695, 1160836, CONICYT-FONDEQUIP EQM150023, IMII P09/16-F (ICM-MINECON), SOCHED 2015-10, CORFO-BMRC 13CTI-21526-P1, and CETREN-UC. EB is a Ph.D. fellow of CONICYT and Faculty of Medicine from Pontificia Universidad Católica de Chile.

2. Martinez-Aguayo A, Fardella C. Genetics of hypertensive syndrome. Horm Res (2009) 71:253-9. doi:10.1159/000208798

3. Franceschini N, Le TH. Genetics of hypertension: discoveries from the bench to human populations. Am J Physiol Renal Physiol (2014) 306:F1-11. doi:10.1152/ajprenal.00334.2013 
4. World Health Organization. Raised Blood Pressure. World Health Organization (2011).p. 39-40. Available from: http://www.who.int/gho/ncd/ risk_factors/blood_pressure_prevalence_text/en/

5. Kearney PM, Whelton M, Reynolds K, Muntner P, Whelton PK, He J. Global burden of hypertension: analysis of worldwide data. Lancet (2005) 365:217-23. doi:10.1016/S0140-6736(05)17741-1

6. Mills KT, Bundy JD, Kelly TN, Reed JE, Kearney PM, Reynolds K, et al. Global disparities of hypertension prevalence and control. Circulation (2016) 134:441-50. doi:10.1161/CIRCULATIONAHA.115.018912

7. Egan BM, Zhao YAR, Egan BM, Zhao Y, Axon RN. US trends in prevalence, awareness, treatment, and control of hypertension, 1988-2008. JAMA (2010) 303:2043-50. doi:10.1001/jama.2010.650

8. Coffman TM. Under pressure: the search for the essential mechanisms of hypertension. Nat Med (2011) 17:1402-9. doi:10.1038/nm.2541

9. Danaei G, Finucane MM, Lin JK, Singh GM, Paciorek CJ, Cowan MJ, et al. National, regional, and global trends in systolic blood pressure since 1980: systematic analysis of health examination surveys and epidemiological studies with 786 country-years and 5.4 million participants. Lancet (2011) 377:568-77. doi:10.1016/S0140-6736(10)62036-3

10. Heidenreich PA, Trogdon JG, Khavjou OA, Butler J, Dracup K, Ezekowitz MD, et al. Forecasting the future of cardiovascular disease in the United States: a policy statement from the american heart association. Circulation (2011) 123:933-44. doi:10.1161/CIR.0b013e31820a55f5

11. Lim SS, Vos T, Flaxman AD, Danaei G, Shibuya K, Adair-Rohani H, et al. A comparative risk assessment of burden of disease and injury attributable to 67 risk factors and risk factor clusters in 21 regions, 1990-2010: a systematic analysis for the global burden of disease study 2010. Lancet (2012) 380:2224-60. doi:10.1016/S0140-6736(12)61766-8

12. Martinez-Aguayo A, Carvajal CA, Campino C, Aglony M, Bolte L, Garcia H, et al. Primary aldosteronism and its impact on the generation of arterial hypertension, endothelial injury and oxidative stress. J Pediatr Endocrinol Metab (2010) 23:323-30. doi:10.1515/jpem.2010.052

13. Johnson RJ, Lanaspa MA, Gabriela Sánchez-Lozada L, Rodriguez-Iturbe B. The discovery of hypertension: evolving views on the role of the kidneys, and current hot topics. Am J Physiol Renal Physiol (2015) 308:F167-78. doi:10.1152/ajprenal.00503.2014

14. Brands MW. Chronic blood pressure control. Compr Physiol. (2012) 2:2481-94. doi:10.1002/cphy.c100056

15. Coffman TM. The inextricable role of the kidney in hypertension. JClin Invest (2014) 124:2341-7. doi:10.1172/JCI72274

16. Funder JW. Primary aldosteronism and salt. Pflugers Arch (2015) 467:587-94. doi:10.1007/s00424-014-1658-0

17. Calhoun DA. Aldosterone and cardiovascular disease: smoke and fire. Circulation(2006)114:2572-4.doi:10.1161/CIRCULATIONAHA.106.668715

18. Stowasser M. Update in primary aldosteronism. JClin Endocrinol Metab (2015) 100:1-10. doi:10.1210/jc.2014-3663

19. Nakamura Y, Yamazaki Y, Konosu-Fukaya S, Ise K, Satoh F, Sasano H. Aldosterone biosynthesis in the human adrenal cortex and associated disorders. J Steroid Biochem Mol Biol (2015) 153:57-62. doi:10.1016/j. jsbmb.2015.05.008

20. Carvajal CA, Herrada AA, Castillo CR, Contreras FJ, Stehr CB, Mosso LM, et al. Primary aldosteronism can alter peripheral levels of transforming growth factor beta and tumor necrosis factor alpha. J Endocrinol Invest (2009) 32:759-65. doi:10.3275/6429

21. Herrada AA, Contreras FJ, Marini NP, Amador CA, González PA, Cortés CM, et al. Aldosterone promotes autoimmune damage by enhancing Th17mediated immunity. J Immunol (2010) 184:191-202. doi:10.4049/jimmunol. 0802886

22. Herrada AA, Campino C, Amador CA, Michea LF, Fardella CE, Kalergis AM. Aldosterone as a modulator of immunity: implications in the organ damage. J Hypertens (2011) 29:1684-92. doi:10.1097/HJH.0b013e32834a4c75

23. Muñoz-Durango N, Barake MF, Letelier NA, Campino C, Fardella CE, Kalergis AM. Immune system alterations by aldosterone during hypertension: from clinical observations to genomic and non-genomic mechanisms leading to vascular damage. Curr Mol Med (2013) 13:1035-46. doi:10.2174/ 1566524011313060015

24. Stehr CB, Mellado R, Ocaranza MP, Carvajal CA, Mosso L, Becerra E, et al. Increased levels of oxidative stress, subclinical inflammation, and myocardial fibrosis markers in primary aldosteronism patients. JHypertens (2010) 28:2120-6. doi:10.1097/HJH.0b013e32833d0177

25. Zhu X, Manning RD, Lu D, Gomez-Sanchez CE, Fu Y, Juncos LA, et al. Aldosterone stimulates superoxide production in macula densa cells. Am JPhysiol Renal Physiol (2011) 301:F529-35. doi:10.1152/ajprenal. 00596.2010

26. Shibata S, Mu S, Kawarazaki H, Muraoka K, Ishizawa K, Yoshida S, et al. Rac1 GTPase in rodent kidneys is essential for salt-sensitive hypertension via a mineralocorticoid receptor-dependent pathway. J Clin Invest (2011) 121:3233-43. doi:10.1172/JCI43124

27. Tapia-Castillo A, Carvajal CA, Campino C, Hill C, Allende F, Vecchiola A, et al. The expression of RAC1 and mineralocorticoid pathway-dependent genes are associated with different responses to salt intake. Am J Hypertens (2015) 28:722-8. doi:10.1093/ajh/hpu224

28. Feldman RD, Limbird LE. GPER (GPR30): a nongenomic receptor (GPCR) for steroid hormones with implications for cardiovascular disease and cancer. Annu Rev Pharmacol Toxicol (2017) 57:567-84. doi:10.1146/ annurev-pharmtox-010716-104651

29. Kuppusamy M, Gomez-Sanchez EP, Beloate LN, Plonczynski M, Naray-Fejes-Toth A, Fejes-Toth G, et al. Interaction of the mineralocorticoid receptor with Rack1 and its role in aldosterone signaling. Endocrinology (2017) 158:2367-75. doi:10.1210/en.2017-00095

30. Pappachan JM, Buch HN. Endocrine hypertension: a practical approach. Adv Exp Med Biol (2017) 956:215-37. doi:10.1007/5584_2016_26

31. Rossi GP, Ceolotto G, Caroccia B, Lenzini L. Genetic screening in arterial hypertension. Nat Rev Endocrinol (2017) 13:289-98. doi:10.1038/ nrendo.2016.196

32. Padmanabhan S, Newton-Cheh C, Dominiczak AF. Genetic basis of blood pressure and hypertension. Trends Genet (2012) 28:397-408. doi:10.1016/j. tig.2012.04.001

33. Carvajal CA, Campino C, Martinez-Aguayo A, Tichauer JE, Bancalari R, Valdivia C, et al. A new presentation of the chimeric CYP11B1/CYP11B2 gene with low prevalence of primary aldosteronism and atypical gene segregation pattern. Hypertension (2012) 59:85-91. doi:10.1161/ HYPERTENSIONAHA.111.180513

34. Carvajal CA, Gonzalez AA, Romero DG, González A, Mosso LM, Lagos ET, et al. Two homozygous mutations in the 11 beta-hydroxysteroid dehydrogenase type 2 gene in a case of apparent mineralocorticoid excess. JClin Endocrinol Metab (2003) 88:2501-7. doi:10.1210/jc.2002021909

35. Levy D, Ehret GB, Rice K, Verwoert GC, Launer LJ, Dehghan A, et al. Genome-wide association study of blood pressure and hypertension. Nat Genet (2009) 41:677-87. doi:10.1038/ng.384

36. Newton-Cheh C, Johnson T, Gateva V, Tobin MD, Bochud M, Coin L, et al. Genome-wide association study identifies eight loci associated with blood pressure. Nat Genet (2009) 41:666-76. doi:10.1038/ng.361

37. Kato N, Takeuchi F, Tabara Y, Kelly TN, Go MJ, Sim X, et al. Meta-analysis of genome-wide association studies identifies common variants associated with blood pressure variation in East Asians. Nat Genet (2011) 43:531-8. doi:10.1038/ng.834

38. Ehret GB, Munroe PB, Rice KM, Bochud M, Johnson AD, Chasman DI, et al. Genetic variants in novel pathways influence blood pressure and cardiovascular disease risk. Nature (2011) 478:103-9. doi:10.1038/nature10405

39. Kelly TN, Takeuchi F, Tabara Y, Edwards TL, Kim YJ, Chen P, et al. Genomewide association study meta-analysis reveals transethnic replication of mean arterial and pulse pressure loci. Hypertension (2013) 62:853-9. doi:10.1161/ HYPERTENSIONAHA.113.01148

40. Wang X, Snieder H. Genome-wide association studies and beyond: what's next in blood pressure genetics? Hypertension (2010) 56:1035-7. doi:10.1161/HYPERTENSIONAHA.110.157214

41. Friso S, Carvajal CA, Fardella CE, Olivieri O. Epigenetics and arterial hypertension: the challenge of emerging evidence. Transl Res (2015) 165:154-65. doi:10.1016/j.trsl.2014.06.007

42. Smith ZD, Meissner A. DNA methylation: roles in mammalian development. Nat Rev Genet (2013) 14:204-20. doi:10.1038/nrg3354

43. Liang M, Cowley AW, Mattson DL, Kotchen TA, Liu Y. Epigenomics of hypertension. Semin Nephrol (2013) 33:392-9. doi:10.1016/j.semnephrol. 2013.05.011 
44. Baccarelli A, Rienstra M, Benjamin EJ. Cardiovascular epigenetics: basic concepts and results from animal and human studies. Circ Cardiovasc Genet (2010) 3:567-73. doi:10.1161/CIRCGENETICS.110.958744

45. Millis RM. Epigenetics and hypertension. Curr Hypertens Rep (2011) 13: 21-8. doi:10.1007/s11906-010-0173-8

46. Friso S, Pizzolo F, Choi S-W, Guarini P, Castagna A, Ravagnani V, et al. Epigenetic control of 11 beta-hydroxysteroid dehydrogenase 2 gene promoter is related to human hypertension. Atherosclerosis (2008) 199:323-7. doi:10.1016/j.atherosclerosis.2007.11.029

47. Smolarek I, Wyszko E, Barciszewska AM, Nowak S, Gawronska I, Jablecka A, et al. Global DNA methylation changes in blood of patients with essential hypertension. Med Sci Monit (2010) 16:CR149-55.

48. Valadi H, Ekström K, Bossios A, Sjöstrand M, Lee JJ, Lötvall JO. Exosomemediated transfer of mRNAs and microRNAs is a novel mechanism of genetic exchange between cells. Nat Cell Biol (2007) 9:654-9. doi:10.1038/ ncb1596

49. Gildea JJ, Carlson JM, Schoeffel CD, Carey RM, Felder RA. Urinary exosome miRNome analysis and its applications to salt sensitivity of blood pressure. Clin Biochem (2013) 46:1131-4. doi:10.1016/j.clinbiochem.2013.05.052

50. Jella KK, Yu L, Yue Q, Friedman D, Duke BJ, Alli AA. Exosomal GAPDH from proximal tubule cells regulate ENaC activity. PLoS One (2016) 11:e0165763. doi:10.1371/journal.pone.0165763

51. Gracia T, Wang X, Su Y, Norgett EE, Williams TL, Moreno P, et al. Urinary exosomes contain microRNAs capable of paracrine modulation of tubular transporters in kidney. Sci Rep (2017) 7:40601. doi:10.1038/srep40601

52. Vlassov AV, Magdaleno S, Setterquist R, Conrad R. Exosomes: current knowledge of their composition, biological functions, and diagnostic and therapeutic potentials. Biochim Biophys Acta (2012) 1820:940-8. doi:10.1016/j.bbagen.2012.03.017

53. Johnstone RM, Adam M, Hammond JR, Orr L, Turbide C. Vesicle formation during reticulocyte maturation. Association of plasma membrane activities with released vesicles (exosomes). J Biol Chem (1987) 262:9412-20. doi:10.1016/j.biocel.2011.10.005

54. Anderson HC. Vesicles associated with calcification in the matrix of epiphyseal cartilage. J Cell Biol (1969) 41:59-72. doi:10.1083/jcb.41.1.59

55. Crawford $\mathrm{N}$. The presence of contractile proteins in platelet microparticles isolated from human and animal platelet-free plasma. Br J Haematol (1971) 21:53-69. doi:10.1111/j.1365-2141.1971.tb03416.x

56. Harding CV, Heuser JE, Stahl PD. Exosomes: looking back three decades and into the future. JCell Biol (2013) 200:367-71. doi:10.4049/jimmunol. 1000541

57. Colombo M, Raposo G, Théry C. Biogenesis, secretion, and intercellular interactions of exosomes and other extracellular vesicles. Annu Rev Cell Dev Biol (2014) 30:255-89. doi:10.1146/annurev-cellbio-101512-122326

58. Raposo G, Stoorvogel W. Extracellular vesicles: exosomes, microvesicles, and friends. J Cell Biol (2013) 200:373-83. doi:10.1083/jcb.201211138

59. Théry C, Amigorena S, Raposo G, Clayton A. Isolation and characterization of exosomes from cell culture supernatants and biological fluids. Curr Protoc Cell Biol (2006) 3:3.22. doi:10.1002/0471143030.cb0322s30

60. Choi D-S, Kim D-K, Kim Y-K, Gho YS. Proteomics of extracellular vesicles: exosomes and ectosomes. Mass Spectrom Rev (2015) 34:474-90. doi:10.1002/ mas. 21420

61. Record M, Carayon K, Poirot M, Silvente-Poirot S. Exosomes as new vesicular lipid transporters involved in cell-cell communication and various pathophysiologies. Biochim Biophys Acta (2014) 1841:108-20. doi:10.1016/j. bbalip.2013.10.004

62. Thakur BK, Zhang H, Becker A, Matei I, Huang Y, Costa-Silva B, et al. Double-stranded DNA in exosomes: a novel biomarker in cancer detection. Cell Res (2014) 24:766-9. doi:10.1038/cr.2014.44

63. Mulcahy LA, Pink RC, Carter DRF. Routes and mechanisms of extracellular vesicle uptake. J Extracell Vesicles (2014) 3:24641. doi:10.3402/jev.v3.24641

64. Ramachandran S, Palanisamy V. Horizontal transfer of RNAs: exosomes as mediators of intercellular communication. Wiley Interdiscip Rev RNA (2012) 3:286-93. doi:10.1002/wrna.115

65. Qi Y, Wang X, Rose KL, MacDonald WH, Zhang B, Schey KL, et al. Activation of the endogenous renin-angiotensin-aldosterone system or aldosterone administration increases urinary exosomal sodium channel excretion. J Am Soc Nephrol (2015) 27:646-56. doi:10.1681/ASN.2014111137
66. Allende F, Solari S, Campino C, Carvajal CA, Lagos CF, Vecchiola A, et al. LC-MS/MS method for the simultaneous determination of free urinary steroids. Chromatographia (2014) 77:637-42. doi:10.1007/s10337-014-2638-4

67. Goligorsky MS, Addabbo F, O’Riordan E. Diagnostic potential of urine proteome: a broken mirror of renal diseases. J Am Soc Nephrol (2007) 18:2233-9. doi:10.1681/ASN.2006121399

68. Kandasamy Y, Smith R, Lumbers ER, Rudd D. Nephrin - a biomarker of early glomerular injury. Biomark Res (2014) 2:21. doi:10.1186/2050-7771-2-21

69. Yadav I, Jhaveri KD. Podocyturia: is there any clinical utility? Indian J Nephrol (2011) 21:219-20. doi:10.4103/0971-4065.85479

70. Spanu S, Van Roeyen CRC, Denecke B, Floege J, Mühlfeld AS. Urinary exosomes: a novel means to non-invasively assess changes in renal gene and protein expression. PLoS One (2014) 9:e109631. doi:10.1371/journal. pone. 0109631

71. Cheng L, Sun X, Scicluna BJ, Coleman BM, Hill AF. Characterization and deep sequencing analysis of exosomal and non-exosomal miRNA in human urine. Kidney Int (2014) 86:433-44. doi:10.1038/ki.2013.502

72. Hoorn EJ, Pisitkun T, Zietse R, Gross P, Frokiaer J, Wang NS, et al. Prospects for urinary proteomics: exosomes as a source of urinary biomarkers. Nephrology (2005) 10:283-90. doi:10.1111/j.1440-1797.2005.00387.x

73. Gildea JJ, Seaton JE, Victor KG, Reyes CM, Bigler Wang D, Pettigrew AC, et al. Exosomal transfer from human renal proximal tubule cells to distal tubule and collecting duct cells. Clin Biochem (2014) 47:89-94. doi:10.1016/j. clinbiochem.2014.06.018

74. Zhou H, Yuen PST, Pisitkun T, Gonzales PA, Yasuda H, Dear JW, et al. Collection, storage, preservation, and normalization of human urinary exosomes for biomarker discovery. Kidney Int (2006) 69:1471-6. doi:10.1038/ sj.ki. 5000273

75. Esteva-Font C, Wang X, Ars E, Guillén-Gómez E, Sans L, González Saavedra I, et al. Are sodium transporters in urinary exosomes reliable markers of tubular sodium reabsorption in hypertensive patients? Nephron Physiol (2010) 114:25-34. doi:10.1159/000274468

76. Lv L-L, Cao Y-H, Pan M-M, Liu H, Tang R-N, Ma K-L, et al. CD2AP mRNA in urinary exosome as biomarker of kidney disease. Clin Chim Acta (2014) 428:26-31. doi:10.1016/j.cca.2013.10.003

77. Wolley MJ, Wu A, Xu S, Gordon RD, Fenton RA, Stowasser M. In primary aldosteronism, mineralocorticoids influence exosomal sodium-chloride cotransporter abundance. J Am Soc Nephrol (2016) 28:56-63. doi:10.1681/ ASN.2015111221

78. Ivy JR, Oosthuyzen W, Peltz TS, Howarth AR, Hunter RW, Dhaun N, et al. Glucocorticoids induce nondipping blood pressure by activating the thiazide-sensitive cotransporter. Hypertension (2016) 67:1029-37. doi:10.1161/ HYPERTENSIONAHA.115.06977

79. Zubiri I, Vivanco F, Alvarez-Llamas G. Proteomic analysis of urinary exosomes in cardiovascular and associated kidney diseases by two-dimensional electrophoresis and LC-MS/MS. Methods Mol Biol (2013) 1000:209-20. doi:10.1007/978-1-62703-405-0_16

80. Pisitkun T, Shen R-F, Knepper MA. Identification and proteomic profiling of exosomes in human urine. Proc Natl Acad Sci U S A (2004) 101:13368-73. doi:10.1073/pnas.0403453101

81. Gonzales PA, Pisitkun T, Hoffert JD, Tchapyjnikov D, Star RA, Kleta R, et al. Large-scale proteomics and phosphoproteomics of urinary exosomes. J Am Soc Nephrol (2009) 20:363-79. doi:10.1681/ASN.2008040406

82. Su SA, Xie Y, Fu Z, Wang Y, Wang JA, Xiang M. Emerging role of exosome-mediated intercellular communication in vascular remodeling. Oncotarget (2015) 8:25700-12. doi:10.18632/oncotarget.14878

83. Liu Y, Rafferty TM, Rhee SW, Webber JS, Song L, Ko B, et al. CD8+ T cells stimulate $\mathrm{Na}-\mathrm{Cl}$ co-transporter NCC in distal convoluted tubules leading to salt-sensitive hypertension. Nat Commun (2017) 8:14037. doi:10.1038/ ncomms14037

84. Baker EH. Ion channels and the control of blood pressure. Br JClin Pharmacol (2000) 49:185-98. doi:10.1046/j.1365-2125.2000.00159.x

85. Wang X, Armando I, Upadhyay K, Pascua A, Jose PA. The regulation of proximal tubular salt transport in hypertension: an update. Curr Opin Nephrol Hypertens (2009) 18:412-20. doi:10.1097/MNH.0b013e32832f5775

86. Krug AW, Papavassiliou F, Hopfer U, Ullrich KJ, Gekle M. Aldosterone stimulates surface expression of NHE3 in renal proximal brush borders. Pflugers Arch (2003) 446:492-6. doi:10.1007/s00424-003-1033-Z 
87. Orlov SN, Koltsova SV, Kapilevich LV, Gusakova SV, Dulin NO. NKCC1 and NKCC2: the pathogenetic role of cation-chloride cotransporters in hypertension. Genes Dis (2015) 2:186-96. doi:10.1016/j.gendis.2015.02.007

88. Koulouridis E, Koulouridis I. Molecular pathophysiology of Bartter's and Gitelman's syndromes. World J Pediatr (2015) 11:113-25. doi:10.1007/ s12519-015-0016-4

89. Salih M, Fenton RA, Zietse R, Hoorn EJ. Urinary extracellular vesicles as markers to assess kidney sodium transport. Curr Opin Nephrol Hypertens (2015) 25:67-72. doi:10.1097/MNH.0000000000000192

90. Mayan H, Attar-Herzberg D, Shaharabany M, Holtzman EJ, Farfel Z. Increased urinary $\mathrm{Na}-\mathrm{Cl}$ cotransporter protein in familial hyperkalaemia and hypertension. Nephrol Dial Transplant (2007) 23:492-6. doi:10.1093/ ndt/gfm641

91. O’Shaughnessy KM. Gordon syndrome: a continuing story. Pediatr Nephrol (2015) 30:1903-8. doi:10.1007/s00467-014-2956-7

92. Fremont OT, Chan JCM. Understanding Bartter syndrome and Gitelman syndrome. World J Pediatr (2012) 8:25-30. doi:10.1007/s12519-012-0333-9

93. Castagna A, Pizzolo F, Chiecchi L, Morandini F, Channavajjhala SK, Guarini P, et al. Circadian exosomal expression of renal thiazide-sensitive $\mathrm{NaCl}$ cotransporter (NCC) and prostasin in healthy individuals. Proteomics Clin Appl (2015) 9:623-9. doi:10.1002/prca.201400198

94. Corbetta S, Raimondo F, Tedeschi S, Syrèn M-L, Rebora P, Savoia A, et al. Urinary exosomes in the diagnosis of Gitelman and Bartter syndromes. Nephrol Dial Transplant (2015) 30:621-30. doi:10.1093/ndt/gfu362

95. Nielsen MR, Frederiksen-Møller B, Zachar R, Jørgensen JS, Hansen MR, Ydegaard R, et al. Urine exosomes from healthy and hypertensive pregnancies display elevated level of $\alpha$-subunit and cleaved $\alpha$ - and $\gamma$-subunits of the epithelial sodium channel-ENaC. Pflugers Arch (2017) 469:1107-19. doi:10.1007/s00424-017-1977-z

96. Olivieri O, Chiecchi L, Pizzolo F, Castagna A, Raffaelli R, Gunasekaran M, et al. Urinary prostasin in normotensive individuals: correlation with the aldosterone to renin ratio and urinary sodium. Hypertens Res (2013) 36:528-33. doi:10.1038/Hr.2012.232

97. Van Der Lubbe N, Jansen PM, Salih M, Fenton RA, Van Den Meiracker AH, Danser AHJ, et al. The phosphorylated sodium chloride cotransporter in urinary exosomes is superior to prostasin as a marker for aldosteronism. Hypertension (2012) 60:741-8. doi:10.1161/ HYPERTENSIONAHA.112.198135

98. Frindt G, Gravotta D, Palmer LG. Regulation of ENaC trafficking in rat kidney. J Gen Physiol (2016) 147:217-27. doi:10.1085/jgp.201511533

99. Oshikawa S, Sonoda H, Ikeda M. Aquaporins in urinary extracellular vesicles (exosomes). Int J Mol Sci (2016) 17:957. doi:10.3390/ijms17060957

100. Takata K, Matsuzaki T, Tajika Y, Ablimit A, Hasegawa T. Localization and trafficking of aquaporin 2 in the kidney. Histochem Cell Biol (2008) 130:197-209. doi:10.1007/s00418-008-0457-0

101. Higashijima Y, Sonoda H, Takahashi S, Kondo H, Shigemura K, Ikeda M. Excretion of urinary exosomal AQP2 in rats is regulated by vasopressin and urinary pH. Am J Physiol Renal Physiol (2013) 305:F1412-21. doi:10.1152/ ajprenal.00249.2013

102. Graffe CC, Bech JN, Lauridsen TG, Vase H, Pedersen EB. Abnormal increase in urinary aquaporin-2 excretion in response to hypertonic saline in essential hypertension. BMC Nephrol (2012) 13:15. doi:10.1186/1471-2369-13-15

103. Andersen H, Friis UG, Hansen PBL, Svenningsen P, Henriksen JE, Jensen BL. Diabetic nephropathy is associated with increased urine excretion of proteases plasmin, prostasin and urokinase and activation of amiloride-sensitive current in collecting duct cells. Nephrol Dial Transplant (2015) 30:781-9. doi:10.1093/ndt/gfu402

104. Kanno K, Sasaki S, Hirata Y, Ishikawa S, Fushimi K, Nakanishi S, et al. Urinary excretion of aquaporin-2 in patients with diabetes insipidus. N Engl J Med (1995) 332:1540-5. doi:10.1056/NEJM199506083322303

105. Sonoda H, Yokota-Ikeda N, Oshikawa S, Kanno Y, Yoshinaga K, Uchida K, etal. Decreased abundance of urinary exosomal aquaporin-1 in renal ischemia-reperfusion injury. Am J Physiol Renal Physiol (2009) 297:F1006-16. doi:10.1152/ajprenal.00200.2009

106. Zhang J, An Y, Gao J, Han J, Pan X, Pan Y, et al. Aquaporin-1 translocation and degradation mediates the water transportation mechanism of acetazolamide. PLoS One (2012) 7:e45976. doi:10.1371/journal.pone.0045976
107. Abdeen A, Sonoda H, Oshikawa S, Hoshino Y, Kondo H, Ikeda M. Acetazolamide enhances the release of urinary exosomal aquaporin-1. Nephrol Dial Transplant (2016) 31:1623-32. doi:10.1093/ndt/gfw033

108. Oosthuyzen W, Scullion KM, Ivy JR, Morrison EE, Hunter RW, Starkey Lewis PJ, et al. Vasopressin regulates extracellular vesicle uptake by kidney collecting duct cells. J Am Soc Nephrol (2016) 27:3345-55. doi:10.1681/ ASN.2015050568

109. Wen H, Frokiaer J, Kwon TH, Nielsen S. Urinary excretion of aquaporin-2 in rat is mediated by a vasopressin-dependent apical pathway. J Am Soc Nephrol (1999) 10:1416-29.

110. Street JM, Birkhoff W, Menzies RI, Webb DJ, Bailey MA, Dear JW. Exosomal transmission of functional aquaporin 2 in kidney cortical collecting duct cells. J Physiol (2011) 589:6119-27. doi:10.1113/jphysiol.2011. 220277

111. Oosthuyzen W, Sime NEL, Ivy JR, Turtle EJ, Street JM, Pound J, et al. Quantification of human urinary exosomes by nanoparticle tracking analysis. J Physiol (2013) 23:5833-42. doi:10.1113/jphysiol.2013.264069

112. Tutakhel OAZ, Jeleń S, Valdez-Flores M, Dimke H, Piersma SR, Jimenez CR, et al. Alternative splice variant of the thiazide-sensitive $\mathrm{NaCl}$ cotransporter: a novel player in renal salt handling. Am J Physiol Renal Physiol (2016) 310:F204-16. doi:10.1152/ajprenal.00429.2015

113. Zhang X-Y, Wang B, Guan Y-F. Nuclear receptor regulation of aquaporin-2 in the kidney. Int J Mol Sci (2016) 17:1105. doi:10.3390/ijms17071105

114. Pironti G, Strachan RT, Abraham D, Mon-Wei Yu S, Chen M, Chen W, et al. Circulating exosomes induced by cardiac pressure overload contain functional angiotensin II type 1 receptors. Circulation (2015) 131:2120-30. doi:10.1161/CIRCULATIONAHA.115.015687

115. Osada-Oka M, Shiota M, Izumi Y, Nishiyama M, Tanaka M, Yamaguchi T, et al. Macrophage-derived exosomes induce inflammatory factors in endothelial cells under hypertensive conditions. Hypertens Res (2016) 40:1-8. doi:10.1038/hr.2016.163

116. Huntzinger E, Izaurralde E. Gene silencing by microRNAs: contributions of translational repression and mRNA decay. Nat Rev Genet (2011) 12:99-110. doi:10.1038/nrg2936

117. Filipowicz W, Bhattacharyya SN, Sonenberg N. Mechanisms of post-transcriptional regulation by microRNAs: are the answers in sight? Nat Rev Genet (2008) 9:102-14. doi:10.1038/nrg2290

118. Hussain MU. Micro-RNAs (miRNAs): genomic organisation, biogenesis and mode of action. Cell Tissue Res (2012) 349:405-13. doi:10.1007/ s00441-012-1438-0

119. Baek D, Villén J, Shin C, Camargo FD, Gygi SP, Bartel DP. The impact of microRNAs on protein output. Nature (2008) 455:64-71. doi:10.1038/ nature 07242

120. Rezaei M, Andrieu T, Neuenschwander S, Bruggmann R, Mordasini D, Frey FJ, et al. Regulation of 11beta-hydroxysteroid dehydrogenase type 2 by MicroRNA. Hypertension (2014) 64:860-6. doi:10.1161/ HYPERTENSIONAHA.114.00002

121. Shang Y, Yang X, Zhang R, Zou H, Zhao R. Low amino acids affect expression of 11 $\beta$-HSD2 in BeWo cells through leptin-activated JAK-STAT and MAPK pathways. Amino Acids (2012) 42:1879-87. doi:10.1007/s00726011-0907-1

122. Liang M, Liu Y, Mladinov D, Cowley AW Jr, Trivedi H, Fang Y, et al. MicroRNA: a new frontier in kidney and blood pressure research. Am JPhysiol Renal Physiol (2009) 297:F553-8. doi:10.1152/ajprenal. 00045.2009

Conflict of Interest Statement: The authors declare that the research was conducted in the absence of any commercial or financial relationships that could be construed as a potential conflict of interest.

Copyright (c) 2017 Barros and Carvajal. This is an open-access article distributed under the terms of the Creative Commons Attribution License (CC BY). The use, distribution or reproduction in other forums is permitted, provided the original author(s) or licensor are credited and that the original publication in this journal is cited, in accordance with accepted academic practice. No use, distribution or reproduction is permitted which does not comply with these terms. 